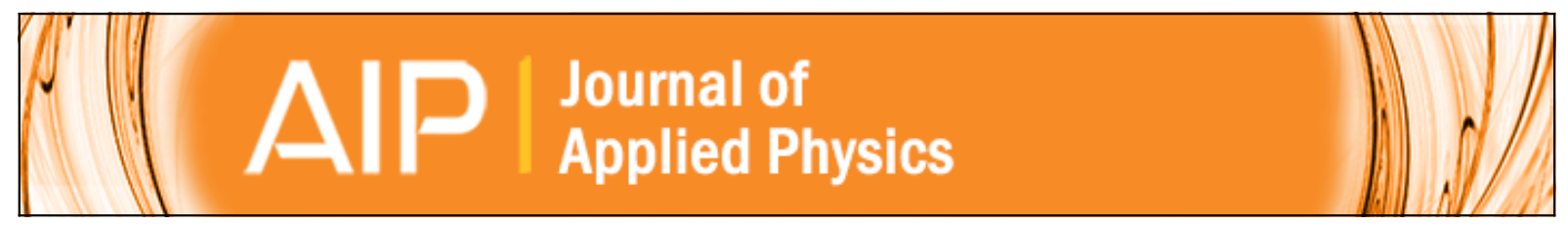

\title{
Very thin Fe/Ni modulation multilayer films under ion bombardment
}

L. Amaral, R. B. Scorzelli, M. E. Brückman, A. Paesano, J. E. Schmidt, T. Shinjo, and N. Hosoito

Citation: Journal of Applied Physics 81, 4773 (1997); doi: 10.1063/1.364679

View online: http://dx.doi.org/10.1063/1.364679

View Table of Contents: http://scitation.aip.org/content/aip/journal/jap/81/8?ver=pdfcov

Published by the AIP Publishing

\section{AlP Re-register for Table of Content Alerts}

\section{Create a profile. \\ Sign up today!}




\title{
Very thin Fe/Ni modulation multilayer films under ion bombardment
}

\author{
L. Amaral \\ Instituto de Física-UFRGS, C.P. 15051, 91501-970 Porto Alegre, Brazil \\ R. B. Scorzelli \\ Centro Brasileiro de Pesquisas Físicas, R. Xavier Sigaud 150, 22290-180 RJ, Brazil \\ M. E. Brückman, A. Paesano, and J. E. Schmidt \\ Instituto de Física-UFRGS, C.P. 15051, 91501-970 Porto Alegre, Brazil \\ T. Shinjo and N. Hosoito \\ Institute for Chemical Research, Kyoto University, Uji, Kyoto-Fu 611, Japan
}

\begin{abstract}
We investigated the effect of noble gas irradiation ( $\mathrm{He}, \mathrm{Ne}$, and $\mathrm{Xe}$ ) on $\mathrm{Fe}-\mathrm{Ni}$ multilayers with a very thin modulation and nominal composition in the Invar region $\mathrm{Fe}_{0.63} \mathrm{Ni}_{0.37}$. The evaluation of the formation/stability of the $\mathrm{Fe}-\mathrm{Ni}$ phases formed under irradiation with different ions and doses was followed by conversion electron Mössbauer spectroscopy. The magnetic hysteresis curves were also obtained in order to correlate the hyperfine pattern with magnetic properties. The as-deposited sample reveals mainly the characteristic $\alpha$-Fe while He- and Ne-irradiated samples clearly show a phase transformation with segregation of $\gamma$-FeNi phases with different $\mathrm{Ni}$ concentrations, a magnetic atomically ordered phase $(\sim 50 \% \mathrm{Ni})$, and a nonmagnetic phase $(\leqslant 30 \% \mathrm{Ni})$. However, mixing with $\mathrm{Ne}$ is more effective than with He for similar doses. The results obtained with Xe showed a large distribution of hyperfine fields similarly to previous results reported for $\mathrm{Kr}$ [C. Tosello, F. Ferrari, R. Brand, W. Keune, G. Marest, M. A. El Khakani, J. Parellada, G. Principi, S. Lo Russo, V. Rigato, and S. Enzo, Nucl. Instrum. Methods B 80/81, 417 (1993)]. (C) 1997 American Institute of Physics. [S0021-8979(97)48508-0]
\end{abstract}

\section{INTRODUCTION}

The observation of anomalies in many high-temperature properties and parameters in $\mathrm{Fe}-\mathrm{Ni}$ alloys indicates that there is a phase instability in the $\mathrm{Fe}-\mathrm{Ni}$ phase system at approximately the Invar composition. ${ }^{1}$ Phase decomposition in thermally annealed $\mathrm{Fe}-\mathrm{Ni}$ material is experimentally difficult to observe because of the slow diffusion rate of $\mathrm{Ni}$ in $\mathrm{Fe}$ at low temperatures. In this context iron-nickel meteorites, due to their extremely slow cooling rates $\left(1{ }^{\circ} \mathrm{C} / 10^{6}\right.$ years) are an unique source of material that allow the study of phase separation in the $\mathrm{Fe}-\mathrm{Ni}$ system. ${ }^{2,3}$ Another alternative way of achieving a state close to the thermodynamical equilibrium, is to use special techniques for increasing diffusion, such as ultrafine particles ${ }^{2,4}$ or ion bombardment in bulk materials. ${ }^{5}$

In this article we investigated the effect of noble gas irradiation $(\mathrm{He}, \mathrm{Ne}$, and $\mathrm{Xe}$ ) on $\mathrm{Fe}-\mathrm{Ni}$ multilayers with nominal composition $\mathrm{Fe}_{0.63} \mathrm{Ni}_{0.37}$, using conversion electron Mössbauer spectroscopy (CEMS) and magnetization measurements.

\section{EXPERIMENT}

The $\mathrm{Fe}-\mathrm{Ni}$ multilayers were prepared using e-gun source in a ultrahigh-vacuum system (better than $5 \times 10^{-8}$ Torr) at the Institute for Chemical Research, Kyoto University. Two hundred Fe and Ni layers, were alternatively deposited to obtain a very thin modulation multilayers of $200 \times\left(\phi_{\mathrm{Fe}}=0.33 \mathrm{~nm}+\phi_{\mathrm{Ni}}=0.18 \mathrm{~nm}\right)$ or a nominal composition $\mathrm{Fe}_{0.63} \mathrm{Ni}_{0.37}$. The ion irradiations were done at the HVEE $400 \mathrm{kV}$ ion implantor of the Institute of Physics, Porto Alegre, with current densities always lower than $1 \mu \mathrm{A} / \mathrm{cm}^{2}$ in order to avoid heating of samples. The implantation ener- gies (He: $14 \mathrm{keV}$; Ne: $70 \mathrm{keV}$; Xe: $400 \mathrm{keV}$ ) were set up using the TRIM code ${ }^{6}$ to match the projected range with middle of sample thickness.

The as-deposited as well as the irradiated samples were characterized by Rutherford backscattering (RBS) in order to investigate sputtering effects during irradiation and reaction with the substrate.

CEMS was performed at room temperature (RT) using a conventional spectrometer with a flowing gas. No texture effects were expected to occur and the CEMS spectra were analyzed using the NORMOS code. ${ }^{7}$

The hysteresis loop curves were measured using an alternating gradient magnetometer (AGM) at RT.

\section{RESULTS AND DISCUSSION}

The characterization by RBS (not shown) clearly indicates that there is no diffusion of $\mathrm{Fe}$ and $\mathrm{Ni}$ toward the substract and no sputtering effects.

The typical CEMS spectra of films irradiated using Ne ions are shown in Fig. 1. The spectrum of the as-deposited sample displays only the typical sextet of bcc $\alpha$-Fe. From $1 \times 10^{16} \mathrm{Ne} / \mathrm{cm}^{2}$ on, the formation of two other $\gamma$-FeNi phases with different $\mathrm{Ni}$ compositions according to their hyperfine parameters can be clearly seen: a magnetic phase atomically ordered $\mathrm{Fe}_{50} \mathrm{Ni}_{50}$ and a nonmagnetic phase $\mathrm{Ni} \leqslant 30 \%$. With increasing doses the ordered phase as well as the nonmagnetic component is enhanced. This two-phase region already observed in particle-irradiated Invar alloys ${ }^{8}$ has also been observed in meteorites ${ }^{2,3}$ and has been considered as the equilibrium state. The CEMS results obtained for a sample of the Santa Catharina meteorite (Fig. 2), can be 


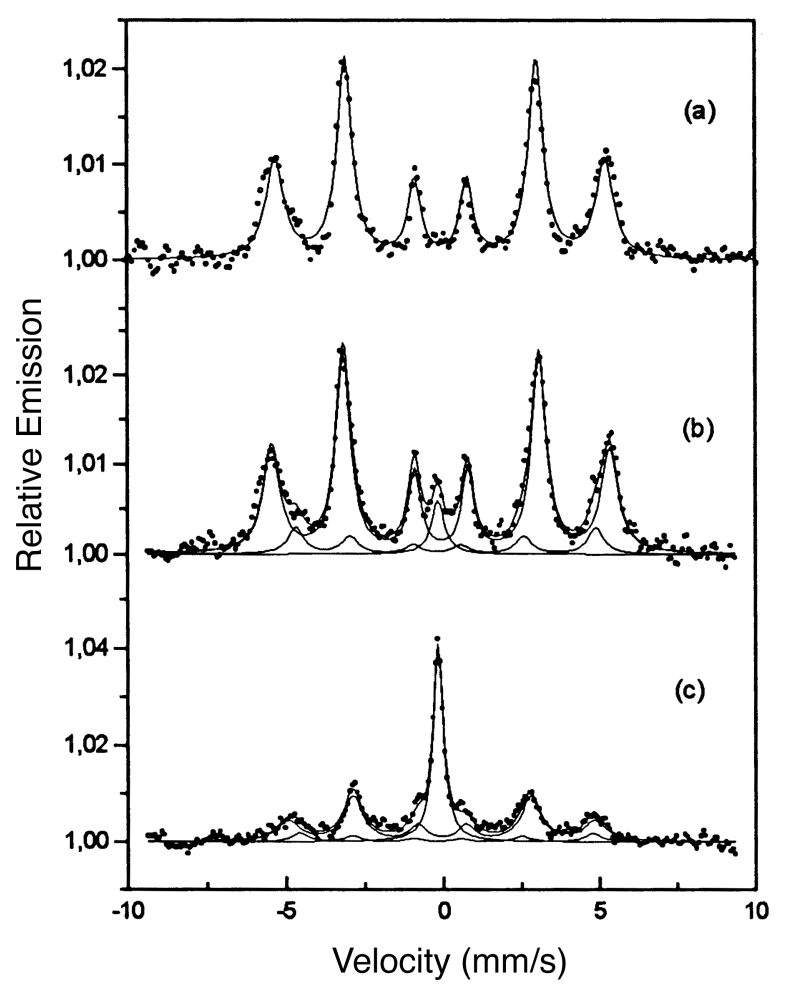

FIG. 1. CEM spectra of Fe-Ni multilayers: (a) as deposited, and Ne irradiated to the doses: (b) $10^{16}$ and (c) $10^{17}$ ions $/ \mathrm{cm}^{2}$.

compared with the Ne-irradiated samples, evidencing the presence of the ordered $\mathrm{Fe}_{50} \mathrm{Ni}_{50}$ phase together with the nonmagnetic phase.

The effect of irradiation with other ions (He, Xe) seen in Fig. 3, shows that irradiation with He causes phase separation but is less effective than with $\mathrm{Ne}$ for similar doses, while Xe-irradiated samples exhibit a hyperfine field distribution

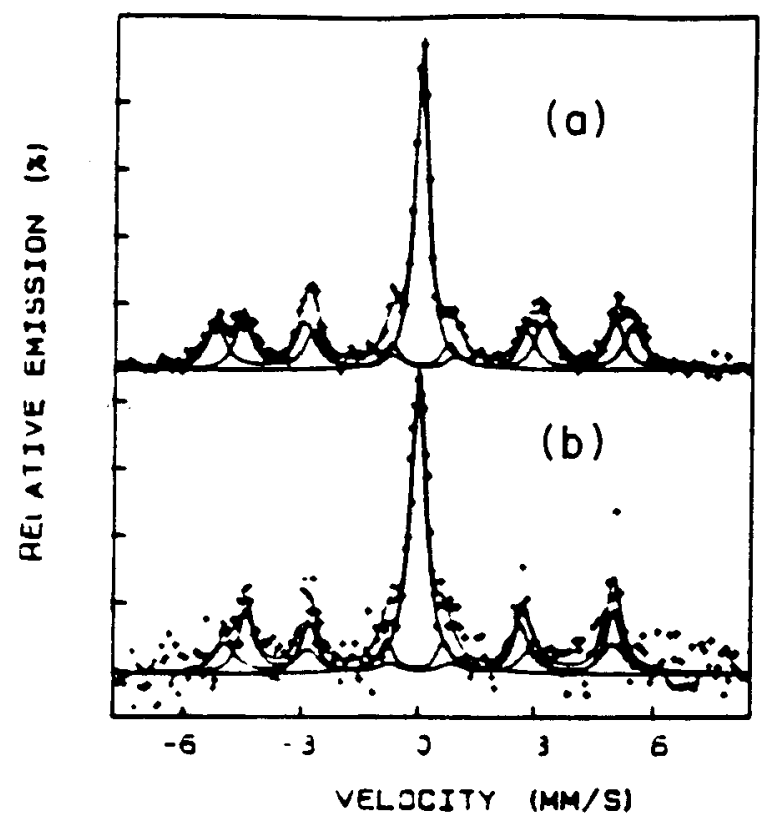

FIG. 2. Mössbauer spectra of the Santa Catharina meteorite: (a) CEMS; (b) $\mathrm{x}$-ray CEMS.

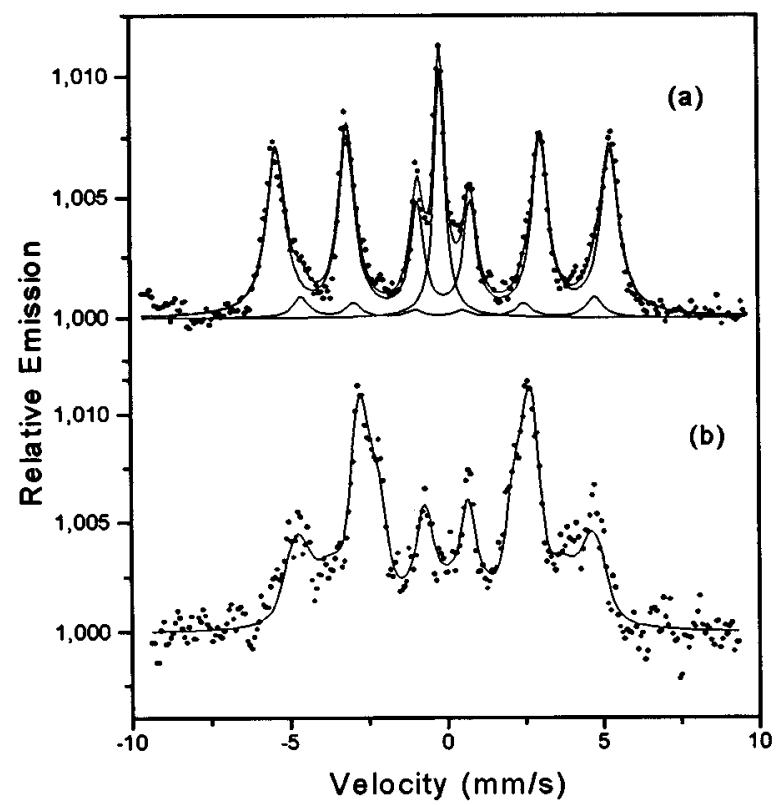

FIG. 3. CEM spectra of Fe-Ni multilayers irradiated to the doses $10^{17}$ ions $/ \mathrm{cm}^{2}$ : (a) He ions; (b) Xe ions.

with a component centered at $29 \mathrm{~T}$ and another one around $23 \mathrm{~T}$ attributed to the Invar phase; nevertheless, the nonmagnetic phase was not detected in the Xe-irradiated sample. This can be due to an instability of this Fe-rich phase in relation to Xe irradiation that seems to favor the formation of phases in the Invar composition.

In Table I the hyperfine parameters as well as the relative area of each phase in the CEMS spectra are presented.

The magnetic hysteresis curves of multilayers measured at RT show the same defined trends. However, the relationships with the CEMS results are not evident and a more coherent interpretation needs more information about microstructural aspects such as grain size, phase growth directions, structural defects. Indeed, as shown in Fig. 4 the sample with higher $\mathrm{Ne}$ dose, which has a major contribution of the nonmagnetic phase (see Table I) to the CEMS spectra, displays a $M-H$ curve (triangle symbols) close to the magnetic asdeposited case. In contrast, in the intermediate dose $10^{16}$

TABLE I. Ion doses, hyperfine parameters, and relative phase area for the $\mathrm{Fe}-\mathrm{Ni}$-irradiated multilayers.

\begin{tabular}{llccr}
\hline \hline \multirow{2}{*}{ Sample } & $\begin{array}{c}H \\
(\mathrm{~T})\end{array}$ & $\begin{array}{c}\mathrm{IS} \\
(\mathrm{mm} / \mathrm{s})\end{array}$ & $\begin{array}{c}\mathrm{EQ} \\
(\mathrm{mm} / \mathrm{s})\end{array}$ & $\begin{array}{c}A \\
(\%)\end{array}$ \\
\hline As dep. & 33 & -0.07 & $\ldots$ & 100 \\
& 33 & -0.06 & $\ldots$ & 82 \\
$10^{16} \mathrm{Ne} / \mathrm{cm}^{2}$ & 29 & 0.05 & 0.15 & 13 \\
& $\ldots$ & -0.17 & $\ldots$ & 5 \\
& 30 & -0.05 & $\ldots$ & 41 \\
$10^{17} \mathrm{Ne} / \mathrm{cm}^{2}$ & 29 & -0.05 & 0.20 & 18 \\
& $\ldots$ & -0.18 & $\ldots$ & 41 \\
& 33 & -0.06 & $\ldots$ & 79 \\
$10^{17} \mathrm{He} / \mathrm{cm}^{2}$ & 29 & -0.07 & 0.15 & 74 \\
& $\ldots$ & -0.18 & $\ldots$ & \\
$10^{17} \mathrm{Xe} / \mathrm{cm}^{2}$ & \multicolumn{5}{c}{ Large magnetic distribution and } \\
& \multicolumn{5}{c}{ only magnetic contributions } \\
\hline \hline
\end{tabular}




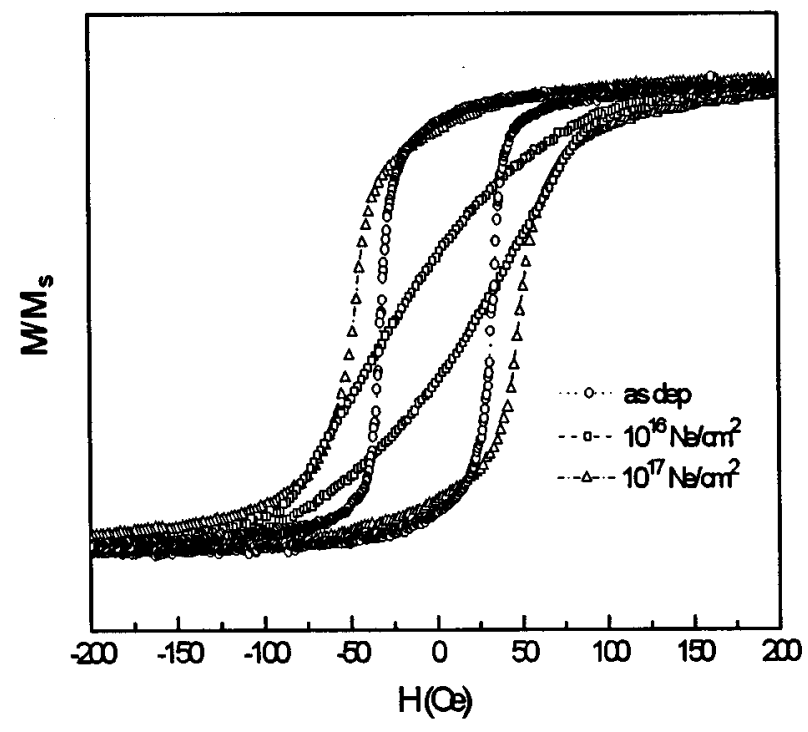

FIG. 4. Magnetic hysteresis curves of $\mathrm{Fe}-\mathrm{Ni}$ multilayers irradiated with $\mathrm{Ne}$ ions: as deposited $(\bigcirc), 10^{16} \mathrm{Ne} / \mathrm{cm}^{2}(\square), 10^{17} \mathrm{Ne} / \mathrm{cm}^{2}(\triangle)$.

$\mathrm{Ne} / \mathrm{cm}^{2}$ (square symbols), where the CEMS spectra reveal only a small fraction (5\%) of this nonmagnetic phase, the hysteresis loop shows a behavior typical of weak magnetic material. On the other hand the mass ion effect presented in Fig. 5 clearly indicates a similar to intermediate $\mathrm{Ne}$ dose behavior, when there is not at all contribution of the nonmagnetic phase (open circles).

\section{CONCLUSION}

The present work on irradiated $\mathrm{Fe}-\mathrm{Ni}$ multilayers with nominal composition in the Invar region shows a route to investigate the formation/stability of close to the thermodynamical phases $\mathrm{Fe}-\mathrm{Ni}$ diagram. A clear phase separation for the Ne irradiation is observed. For dose as high as $10^{17}$ $\mathrm{Ne} / \mathrm{cm}^{2}$ a significative contribution such as meteorite ordered $\mathrm{Fe}_{50} \mathrm{Ni}_{50}$ is obtained. The same effect occurs also in the irradiation with $\mathrm{He}$ ions but a smaller contribution of the ordered phase is achieved. In the case of Xe-irradiated sample a large magnetic hyperfine field is observed in accordance with pre-

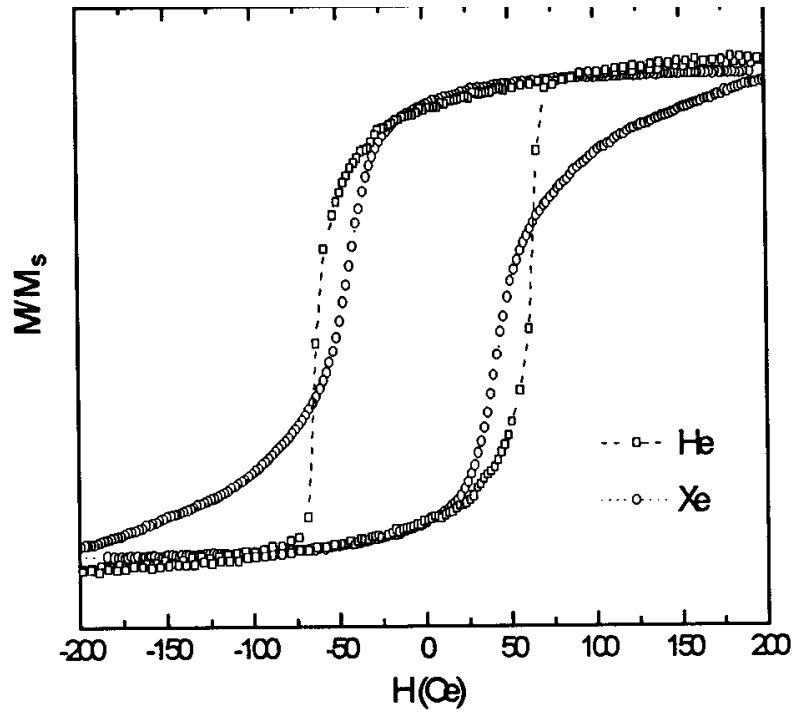

FIG. 5. Magnetic hysteresis curves of $\mathrm{Fe}-\mathrm{Ni}$ multilayers irradiated $10^{17}$ $\mathrm{He} / \mathrm{cm}^{2}(\square), 10^{17} \mathrm{Ne} / \mathrm{cm}^{2}(\bigcirc)$.

vious related experiments for other heavy ions. ${ }^{9,6}$ The $H-M$ measurements show a complex behavior and no straightforward relation could be done with the clear phase separation revealed by the Mössbauer results.

${ }^{1}$ K. B. Reuter, D. B. Williams, and J. I. Goldstein, Metall. Trans. A 2, 719 (1989).

${ }^{2}$ J. F. Albertsen, G. B. Jensen, and J. M. Knudsen, Nature (London) 273, 453 (1978).

${ }^{3}$ J. Danon, R. B. Scorzelli, I. Souza Azevedo, W. Curvello, J. F. Albertsen, and J. M. Knudsen, Nature (London) 277, 283 (1979).

${ }^{4}$ H. Franco and H. Rechenberg, J. Phys. F 15, 719 (1985).

${ }^{5}$ M. R. Gallas, L. Amaral, and J. A. H. da Jornada, J. Appl. Phys. 70, 131 (1991)

${ }^{6}$ J. F. Ziegler, J. P. Biersack and U. Littmark, in The Stopping and Range of Ions in Solids, edited by J. F. Ziegler (Pergamon, New York, 1985), Vol. 1.

${ }^{7}$ R. A. Brand, Nucl. Instrum. Methods Phys. Res. B 28, 398 (1987).

${ }^{8}$ A. Chamberod, J. Laugier, and J. M. Penisson, J. Magn. Magn. Mater. 10, 139 (1979).

${ }^{9}$ C. Tosello, F. Ferrari, R. Brand, W. Keune, G. Marest, M. A. El Khakani, J. Parellada, G. Principi, S. Lo Russo, V. Rigato, and S. Enzo, Nucl. Instrum. Methods Phys. Res. B 80/81, 417 (1993). 